\title{
Preparation of a Monoclonal Antibody Against Saikosaponin C and the Establishment of its Enzyme-Linked Immunosorbent Assay
}

Baoping Qu ${ }^{1}$, Jiayang Sai ${ }^{2}$, Huihua Qu ${ }^{3}$, Shuchen Liu ${ }^{1}$, Jinjun Cheng ${ }^{4}$, Wenchao Shan ${ }^{4}$, Yan Zhao*2 and Qingguo Wang ${ }^{2}$

${ }^{1}$ School of Basic Medical Sciences, Beijing University of Chinese Medicine, 11 Beisanhuandong Road, Chaoyang District, Beijing, 100029, P.R. China

${ }^{2}$ The Third Affiliated Hospital, Beijing University of Chinese Medicine, 11 Beisanhuandong Road, Chaoyang District, Beijing, 100029, P.R. China

${ }^{3}$ Center of Scientific Experiment, Beijing University of Chinese Medicine, 11 Beisanhuandong Road, Chaoyang District, Beijing, 100029, P.R. China

${ }^{4}$ School of Chinese Materia Medica, Beijing University of Chinese Medicine, 11 Beisanhuandong Road, Chaoyang District, Beijing, 100029, P.R. China

\begin{abstract}
A monoclonal antibody (MAb) 1E11D8 against saikosaponin c (SSc) was prepared by a cell fusion with splenocytes and hypoxanthine-aminopterin-thymidine-sensitive mouse myeloma SP2/0 cell line. The prepared anti-SSc MAb1E11D8 has a novel characteristic which shows high specific for saikosaponin c, saikosaponin d and saikosaponin a, three major oleanane-saponins in Radix Bupleuri. By using anti-SSc MAb-1E11D8, a realiable ELISA was developed for the detection of SSc. The system shows a full measuring range from $156.25 \mathrm{ng} \cdot \mathrm{mL}^{-1}$ to $2500 \mathrm{ng} \cdot \mathrm{mL}^{-1}$ in the case of $\mathrm{SSc}$ in indirect competitive ELISA (icELISA). The regression equation was $y=-0.283 \ln (C)+2.3301$ with a correlation coefficient of 0.99 . Precision and accuracy of the icELISA method were evaluated by the variations between replicates from well to well (intra-assay) and plate to plate (inter-assay). The values obtained for these parameters were within the normal range $(<10 \%)$. The recovery rates ranged from 99.82 to $103.59 \%$. The ELISA method was further validated to be of use for surveying SSc in traditional Chinese prescriptions.
\end{abstract}

Keywords: Saikosaponins; Saikosaponin c; Monoclonal antibody; Immunoassays; Enzyme-linked immunosorbent assay

\section{Introduction}

Immunoassays are preferable in the field of clinical analysis for viral proteins for years [1]. Recently, various enzyme-linked immuosorbent assays (ELISA) for small molecules have been developed for both quantitative and qualitative analysis [2-5] due to the merit such as high throughput, simplicity, high reproducibility and sensativity. In our outgoing study, we have developed the preparation of MAbs against baicalin, puerarin, geniposide, hyodeoxycholic acid, Glycyrrhizic acid, paeoniflorin, ginsensoide Re, ginsenoside $\mathrm{Rh} 1$ and established their ELISA method [6-10]. Consequently, we applied the assays to study the pharmacokinetics and pharmacokinetic interactions between these bioactive compounds. The comparably low quantities of specimen required such as little as $5 \mu \mathrm{L}$ of serum for determination in mice is really a merit for pharmacokinetic study. The ELISA method we developed is proved to be more suitable for quality control and pharmacokinetic study on traditional Chinese medicine compared with high-performance liquid chromatographic (HPLC) analyses since it can detect samples with little pretreatment.

Saikosaponin c (SSc) is one of the active ingredients isolated from Radix bupleuri, a traditional Chinese medicine which plays an important role in human disease prevention and treatment. Recent study has demonstrated that SSc represents a promising therapeutic candidate for the treatment of vascular endothelial cell injury and cellular dysfunction [11]. Until now, several HPLC analyses have been developed for the qualitative ananlysis of SSc [12]. However, because SSc do not exhibit any absorption maximum in the ultraviolet (UV) region above $220 \mathrm{~nm}$, it was usually analyzed below $210 \mathrm{~nm}$ and therefore it could not be easily detected by HPLC [13]. The disadvantages of these methods continue to be high cost and limited availability. In view of these limitations, we sought to develop a more practical method for SSc based on our previous studies on the development of immunochemical techniques using monoclonal antibodies (MAbs) against small molecular weight compounds (Figure 1).

In this study, we developed a novel analysis method for determining

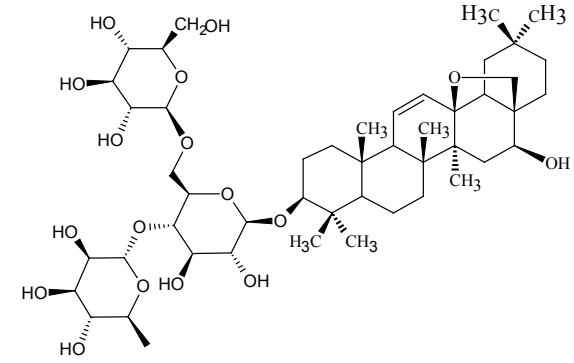

Figure 1: Chemical structure of the saikosaponin c.

SSc by using immunological technique. Monoclonal antibodies (MAbs) against SSc were prepared and used in enzyme-linked immunosorbent assay (ELISA) for analysis of SSc. This is the first report for determining SSc by ELISA system. Preparation of MAbs against SSc and its application to ELISA system are demonstrated in this paper.

\section{Experimental}

\section{Reagents and chemicals}

The 96-well immunoplates were purchased from Corning Incorporated. Bovine serum albumin (BSA), ovalbumin (OVA), medium were obtained from Sigma-Aldrich Co., Ltd. Saikosaponin d,

*Corresponding author: Yan Zhao, Beijing University of Chinese Medicine School of Basic Medical Sciences, 11 Beisanhuandong Road, Chaoyang District, Beijing, P.R. China, Tel: +86 16428 6705; Fax: +86 16428 6821; E-mail: zhaoyandr@gmail.com

Received: July 13, 2015; Accepted: July 24, 2015; Published July 27, 2015

Citation: Qu B, Sai J, Qu H, Liu S, Cheng J, et al. (2015) Preparation of a Monoclonal Antibody Against Saikosaponin $\mathrm{C}$ and the Establishment of its EnzymeLinked Immunosorbent Assay. Biochem Anal Biochem 4: 196. doi:10.4172/21611009.1000196

Copyright: (c) 2015 Qu B, et al. This is an open-access article distributed under the terms of the Creative Commons Attribution License, which permits unrestricted use, distribution, and reproduction in any medium, provided the original author and source are credited. 
saikosapoin a, saikosapoin b1, saikosapoin b2, saikosaponin $\mathrm{c}$ and all other compounds were purchased from Chengdu Pufei De Biotech Co., Ltd and all had a purity of $98 \%$. TMB was supplied by Sigma Co., Ltd. Peroxidase-labeled anti-mouse immunoglobulin G (IgG) was provided by Organon Teknika Cappel Products. Chinese medicines used in this paper were obtained from Beijing Tong Ren Tang Group Co., Ltd. (Beijing, China). All other chemical reagents of analytical grade were obtained from Sinopharm Chemical Reagents Beijing Co., Ltd

\section{Apparatus}

An electronic balance (BS124-S) was procured from Sartorius AG. A spectrophotometric microtiter reader (for absorbance measurements) was obtained from Thermo Fisher Scientific (Multiskan MK3). Deionized water was prepared using an ultra-class ultraviolet (UV) plus water purification system (SG Co., Ltd.). Immunoreactions were carried out in an electro-heated standing-temperature cultivator (DRP-9082) purchased from Sumsung Experiment Instrument Co., Ltd.

\section{Buffers}

The compositions of the buffers and solutions used in this study were as follows: phosphate-buffered saline (PBS) $\mathrm{NaCl}\left(137 \mathrm{mmol} \cdot \mathrm{mL}^{-1}\right)$, $\mathrm{Na}_{2} \mathrm{HPO}_{4} \cdot 12 \mathrm{H}_{2} \mathrm{O}\left(10 \mathrm{mmol} \cdot \mathrm{mL}^{-1}\right), \mathrm{KCl}\left(2.68 \mathrm{mmol} \cdot \mathrm{mL}^{-1}\right)$, and $\mathrm{KH}_{2} \mathrm{PO}_{4}$ (1.47 mmol-mL-1), pH 7.4; carbonate-buffered saline- $\mathrm{Na}_{2} \mathrm{CO}_{3}(15$ $\left.\mathrm{mmol} \cdot \mathrm{mL}^{-1}\right), \mathrm{NaHCO}_{3}\left(35 \mathrm{mmol} \cdot \mathrm{mL}^{-1}\right), \mathrm{pH} 9.6$; washing buffer, $\mathrm{PBS}$ with $0.05 \%$ Tween-20 (PBS-T); blocking buffer, $1 \%$ gelatin in deionized water; TMB substrate solution, combination of Part A $(10 \mathrm{~mL} ; 24.3 \mathrm{~mL}$ of $0.1 \mathrm{~mol} \cdot \mathrm{mL}^{-1}$ citric acid, $25.7 \mathrm{~mL}$ of $0.2 \mathrm{~mol} \cdot \mathrm{mL}^{-1} \mathrm{Na}_{2} \mathrm{HPO}_{4}$, and 50 $\mathrm{mL}$ of deionized water), Part $\mathrm{B}\left(0.5 \mathrm{~mL} ; 2 \mathrm{~mol} \cdot \mathrm{mL}^{-1}\right.$ of TMB in ethanol), and Part C $\left(32 \mu \mathrm{L}\right.$ of $\left.0.75 \% \mathrm{H}_{2} \mathrm{O}_{2}\right)$; stopping solution, $2 \mathrm{~mol} \cdot \mathrm{mL}^{-1} \mathrm{H}_{2} \mathrm{SO}_{4}$.

\section{Preparation of anti-SSc MAb}

Saikosaponin c-bovine serum albumin conjugates (SSc-BSA) were synthesized using a periodate oxidation procedure based on a previously reported method with some modifications $[14,15]$. Briefly, SSc was dissolved in methanol at $10 \mathrm{mg} \cdot \mathrm{mL}^{-1}$. Then, $1 \mathrm{~mL}$ of a freshly prepared odium periodate $(0.1 \mathrm{M})$ was dropped into $1 \mathrm{~mL}$ of SSc solution. After stirring at $25^{\circ} \mathrm{C}$ for $1 \mathrm{~h}, 50 \mathrm{mM}$ carbonate buffer solution $(\mathrm{pH} 9.6,1 \mathrm{~mL}$ ) containing BSA $(10 \mathrm{mg})$ was added to the reaction mixture. $\mathrm{pH}$ was adjusted to 10 using $1 \mathrm{M} \mathrm{Na}_{2} \mathrm{CO}_{3}$ solution and the mixture was stirred at $25^{\circ} \mathrm{C}$ for $5 \mathrm{~h}$. Then the mixture was dialyzed 6 times against CBS for $72 \mathrm{~h}$. The SSc-OVA conjugate was synthesized using the same method as above.

$\mathrm{BALB} / \mathrm{c}$ female mice ( 6 weeks of age) were immunized with the SSc-BSA conjugate. Joint Ethical Review Committee of the Beijing University of Chinese Medicine has approved our ethics application for animals. The first immunization $(50 \mu \mathrm{g}$ conjugate per injection) consisted of a subcutaneous multipoint injection in the back using a 1:1 emulsion of the conjugate to Freund's complete adjuvant. The subsequent immunizations ( $50 \mu \mathrm{g}$ conjugate per injection) were administered as a 1:1 emulsion in Freund's incomplete adjuvant and performed at 2 week intervals. At the fourth and final immunization, a booster dose of 100 $\mu \mathrm{g}$ of conjugate dissolved in PBS without adjuvant was administered intraperitoneally. On the third day after the final immunization, splenocytes were isolated and fused with a hypoxanthine-aminopterinthymidine (HAT)-sensitive mouse myeloma cell line (Sp2/0-Ag14) by the polyethylene glycol (PEG) method. Hybridomas secreting MAbs that were reactive to SSc were cloned by the limited dilution method. Established hybridomas were cultured in hypoxanthine-thymidine (HT) medium.
Individual anti-SSc MAb was purified using a protein $\mathrm{G} F \mathrm{~F}$ column $(0.46 \times 11 \mathrm{~cm}$; GE Healthcare, USA) [16]. The ascites $(50 \mathrm{~mL})$ containing MAb was adjusted to $\mathrm{pH} 7$ with $1 \mathrm{M}$ Tris solution and loaded onto the column. The column was then washed with $20 \mathrm{mM}$ phosphate buffer ( $\mathrm{pH} 7.2$ ) and the adsorbed antibody was eluted with $0.1 \mathrm{M}$ of glycine buffer ( $\mathrm{pH}$ 2.7). The eluted antibody was neutralized with $1 \mathrm{M}$ Tris solution, dialyzed against $50 \times$ volumes of water for five changes at $4^{\circ} \mathrm{C}$, and then lyophilized.

Determination of the MAb isotypes was carried out according to the instructions of the Mouse Monoclonal Antibody Isotype Kit. A sandwich ELISA method was applied to identify the subclasses of monoclonal antibodies against SSc.

The reactivity of anti-SSc MAb to SSc-OVA was determined by indirect ELISA (iELISA). SSc-OVA $(100 \mu \mathrm{L} /$ well) diluted in 50 $\mathrm{mM}$ carbonate buffer ( $\mathrm{pH}$ 9.6) was added into the wells of a 96-well immunoplate and incubated for $1 \mathrm{~h}$. This was then treated with 200 $\mu \mathrm{L}$ of blocking buffer (phosphate-buffered saline containing $5 \%$ skim milk, SPBS) for $2 \mathrm{~h}$ to eliminate non-specific adsorption. The plate was washed three times with washing buffer (phosphate-buffered saline containing $0.05 \%$ Tween 20, PBST) and filled with $100 \mu \mathrm{L}$ of MAb solution at various dilutions in different rows. After $1 \mathrm{~h}$, the plate was washed three times with PBST and incubated with $100 \mu \mathrm{L}$ of a 10,000 fold diluted peroxidase-labeled goat anti-mouse IgG solution for $0.5 \mathrm{~h}$, followed by another wash with PBST for three times. Then $100 \mu \mathrm{L}$ of the substrate solution $\left(0.1 \mathrm{mM}\right.$ citrate buffer containing $0.75 \% \mathrm{H}_{2} \mathrm{O}_{2}$ and $2 \mathrm{mg} / \mathrm{mL}$ 3,3,5,5'-tetramethylbenzi-dine (TMB)) was added to each well, and the plate was incubated for $15 \mathrm{~min}$. The reaction was then terminated by adding $50 \mu \mathrm{L}$ of $2 \mathrm{M}$ sulfuric acid to each well. All reactions were carried out at $37^{\circ} \mathrm{C}$. The absorbance was determined at $450 \mathrm{~nm}$ using a Biotek.

For indirect competitive ELISA (icELISA), SSc-OVA (1:10,000, 100 $\mu \mathrm{L} /$ well) was adsorbed in the wells of a 96-well immunoplate, which was then treated with $200 \mu \mathrm{L}$ of $5 \%$ SPBS for $2 \mathrm{~h}$ to reduce non-specific adsorption. The plate was washed three times with PBST, and $50 \mu \mathrm{L}$ of various concentrations of SSc solution were incubated with $50 \mu \mathrm{L}$ of MAb solution for $1 \mathrm{~h}$. The subsequent process was the same as that described for iELISA.

\section{Validation of the icELISA Method}

icELISA was used with SSc-OVA as the solid phased antigen and IgG solution. A range of SSc amounts was separately added to compete with the coated antigen. From this competition assay, a standard curve of inhibition for the measured range was created. Furthermore, the cross-reactivities (CRs, \%) of SSc with structurally related compounds were determined according to Weiler and Zenk's equation [17].

Several concentrations of SSc were measured with the developed icELISA method for six times in a day to determine the accuracy and variation of intra-assay (well to well), and for six consecutive days to determine that of inter-assay (plate to plate and day to day), which were all expresses by RSDs (\%). Various concentrations of SSc were added for icELISA to calculate aassay recovery rate. For each level, six samples were analyzed, and the concentrations of SSc was determined by the icELISA.

An Agilent series 1260 HPLC instrument equipped with a quaternary pump, a diode-array detector, an autosampler and a column compartment was used for HPLC analyses. The sample was separated on a phenomenex luna $5 \mathrm{u}$ C18(2) $100 \mathrm{~A}$ column $(5 \mu \mathrm{m}, 4.60 \times 250$ 
Citation: Qu B, Sai J, Qu H, Liu S, Cheng J, et al. (2015) Preparation of a Monoclonal Antibody Against Saikosaponin C and the Establishment of its Enzyme-Linked Immunosorbent Assay. Biochem Anal Biochem 4: 196. doi:10.4172/2161-1009.1000196

Page 3 of 4

$\mathrm{mm}$, phenomenex, USA), by isocratic elution with the mobile phase composed of water and $\mathrm{CH} 3 \mathrm{CN}(43 / 57, \mathrm{~V} / \mathrm{V})$ at a flow rate of 1.0 $\mathrm{mL} \cdot \mathrm{min}^{-1}$, and analyzed by diode array detector with an excitation and emission wavelength of $203 \mathrm{~nm}$. The chromatogram was recorded at $203 \mathrm{~nm}$ and the spectral data for all peaks were obtained in the range of $190-400 \mathrm{~nm}$. The column temperature was kept constantly at $25^{\circ} \mathrm{C}$.

All TCMs in a prescription were weighed in propotion, powdered and mixed together, and then $500 \mathrm{mg}$ of the powder were extracted with $\mathrm{MeOH}(50 \mathrm{~mL})$ under sonication five times, filtered using the Cosmonice filter $\mathrm{W}$ (pore size, $0.45-\mu \mathrm{m}$ ), and evaporated. The residues were redissolved in $5 \mathrm{~mL}$ of $\mathrm{MeOH}$, and then the final sample solutions were diluted with deionized water properly when analyzed by icELISA.

\section{Results and Discussion}

Hyper-immunized BALB/c mice used to derive the cell clones described in this paper yielded splenocytes that were fused with a HAT-sensitive SP2/0 myeloma cell line according to the protocols established in this laboratory. A hybridroma-producing MAb reactive to SSc was obtained and named MAb-1E11D8. BALB/c male mice were intraperitoneally injected with 1E11D8 to induce ascites to obtain anti-SSc MAb. A sandwich ELISA method was employed to identify the subtype of the monoclonal antibody against SSc using the MAb isotyping kit. The data shows that the anti-SSc MAb-1E11D8 having lanmuda light chains was classified into the IgG1 subclass antibody group.

Sensitivity were analyzed by icELISA method. The 96-well immunoplate was coated with $1 \mu \mathrm{g} \cdot \mathrm{mL}^{-1}$ SSc-OVA and the optimal concentration of anti-SSc MAb was screened by iELISA. Various amounts of SSc were added to compete with the coated antigen from which the standard curve of inhibition was created. Figure 2 shows the competitive inhibition between the MAb and SSc-OVA produced by various concentrations of SSc by icELISA. Under this condition, a linear relationship between optical density and doses in the range of $156.25-2500 \mathrm{ng} \cdot \mathrm{mL}^{-1}\left(\mathrm{R}^{2}=0.99\right)$ could be achieved with a half-maximal inhibitory concentration of $625 \mathrm{ng} \cdot \mathrm{mL}^{-1}$.

Assay specificities were examined by icELISA with various related compounds, and the cross-reactivity rates (CRs) were calculated following Weiler and Zenk's method [17]. As shown in Table 1, antiSSc MAb-1E11D8 reacted with SSa, and SSd at rates of $31.25 \%$ and $126.25 \%$, respectively, but has no reactivity with other similar saponins and flavonoids. The higher reactivity to SSc, SSd, and SSa indicates that the SSc MAb can be used to determine SSc, SSa and SSd, which are major constituents of Radix bupleuri, thus it can be applied into quality control of Radix bupleuri.

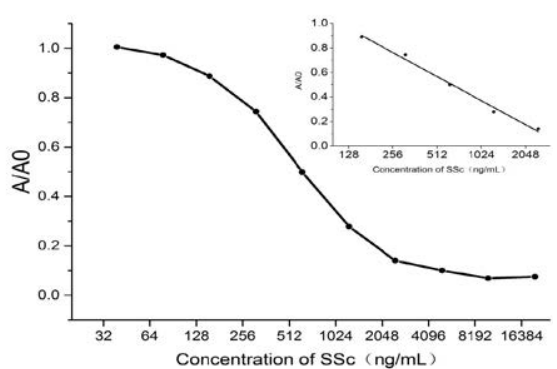

Figure 2: Calibration curve of saikosaponin c. Various concentrations of saikosaponin c were incubated with monoclonal antibodies in wells pre-coated with saikosaponin c-OVA $\left(1 \mu \mathrm{g} \cdot \mathrm{mL}^{-1}\right)$. After washing with PBS-T, the wells were again incubated with peroxidase-labeled anti-mouse immunoglobulin $G$ and absorbance was measured at $450 \mathrm{~nm}$.

\begin{tabular}{|c|c|c|}
\hline Classification & Compounds & Cross-reactivity ${ }^{\mathrm{a}}(\%)$ \\
\hline \multirow{9}{*}{ Triterpenes } & Saikosaponin c & 100 \\
\hline & Saikosaponin d & 126.25 \\
\hline & Saikosaponin a & 31.25 \\
\hline & Saikosaponin b1 & $<0.09$ \\
\hline & Saikosaponin b2 & $<0.09$ \\
\hline & Ginsenoside Re & $<0.09$ \\
\hline & Ginsenoside Rg2 & $<0.09$ \\
\hline & Ginsenoside Rb1 & $<0.09$ \\
\hline & Notoginsenoside & $<0.09$ \\
\hline \multirow{2}{*}{ Terpenes } & Glycyrrhizic acid & $<0.09$ \\
\hline & Paeoniflorin & $<0.09$ \\
\hline \multirow{5}{*}{ Flavonoids } & Gardenoside & $<0.09$ \\
\hline & Puerarin & $<0.09$ \\
\hline & Baicalin & $<0.09$ \\
\hline & Hesperidin & $<0.09$ \\
\hline & Rutin & $<0.09$ \\
\hline \multirow{5}{*}{ Alkaloids } & Icariin & $<0.09$ \\
\hline & Matrine & $<0.09$ \\
\hline & Theophylline & $<0.09$ \\
\hline & Evodia rutaecarpa alkali & $<0.09$ \\
\hline & Amygdalin & $<0.09$ \\
\hline \multirow{7}{*}{ Other } & Aloe glucoside & $<0.09$ \\
\hline & Salvianolic acid A & \\
\hline & Chlorogenic acid & $<0.09$ \\
\hline & Timosaponin A & $<0.09$ \\
\hline & Eleutheroside B & $<0.09$ \\
\hline & Eleutheroside D & $<0.09$ \\
\hline & Gallic acid & $<0.09$ \\
\hline
\end{tabular}

The cross-reactivities were determined according to Weiler's equation.

Table 1: Cross-reactivities (\%) of MAb-1E11D8 against various compounds

\begin{tabular}{|c|c|c|c|c|}
\hline \multirow{2}{*}{$\mathbf{S S c}$} & \multicolumn{2}{|c|}{ Intra-assay } & \multicolumn{2}{c|}{ Inter-assay } \\
\cline { 2 - 5 }$\left(\mathbf{n g} \cdot \mathbf{m L}^{\mathbf{1}} \mathbf{)}\right.$ & $\begin{array}{c}\text { Concentration } \\
\text { (ng· mL-1) }\end{array}$ & RSD (\%) & $\begin{array}{c}\text { Concentration } \\
\left(\mathbf{n g} \cdot \mathbf{m L}^{-1} \text { ) }\right.\end{array}$ & RSD (\%) \\
\hline 0.00 & 0.00 & 1.90 & 0.00 & 6.10 \\
\hline 156.25 & $165.30 \pm 12.38$ & 7.49 & $147.75 \pm 10.50$ & 7.10 \\
\hline 312.5 & $320.45 \pm 19.56$ & 6.10 & $325.08 \pm 10.52$ & 3.24 \\
\hline 625 & $621.46 \pm 3.54$ & 4.99 & $601.01 \pm 23.56$ & 7.25 \\
\hline 1250 & $1261.76 \pm 9.75$ & 0.77 & $1230.86 \pm 19.14$ & 9.09 \\
\hline
\end{tabular}

accuracy was evaluated by the determination of five concentrations of saikosaponin c. Six replicate wells of each were executed and indicated as mean $\pm \mathrm{SD} .{ }^{\mathrm{b}}$ Assay variation was described by RSD (\%) of intra- and inter-assays. All measured values are mean \pm SD for six replicate wells each.

Table 2: Assay accuracy and variation ${ }^{\mathrm{b}}$

\begin{tabular}{|c|c|c|}
\hline Added amount $\left.\mathbf{( n g} \cdot \mathbf{m L}^{-1}\right)$ & Mean value $\left.^{\mathbf{a}} \mathbf{( n g} \cdot \mathbf{m L}^{-1}\right)$ & Recovery $^{\mathbf{b}} \mathbf{( \% )}$ \\
\hline 0.00 & 0.00 & \\
\hline 200 & $204.06 \pm 4.06$ & 102.02 \\
\hline 400 & $410.06 \pm 5.12$ & 102.51 \\
\hline 600 & $601.63 \pm 3.01$ & 103.59 \\
\hline 1200 & $1206.85 \pm 6.03$ & 100.60 \\
\hline 2400 & $2395.66 \pm 0.48$ & 99.82 \\
\hline & & Average 101.71 \\
\hline
\end{tabular}

aAll data are mean \pm SD from triplicate wells of each sample. bThe zero level was used as control and the recovery rate was calculated as follows: recovery $(\%)=$ measured amount/added amount $\times 100 \%$.

Table 3: Assay recovery rate 


\begin{tabular}{|c|r|l|l|l|}
\hline \multicolumn{5}{|c|}{ content of SSc $\left(\boldsymbol{\mu g} \cdot \mathbf{m L}^{-1}\right)$} \\
\hline sample & \multicolumn{1}{|c|}{ ELISA } & RSD $\%$ & HPLC & RSD\% \\
\hline 1 & $410.06 \pm 5.12$ & 1.25 & $383.09 \pm 12.23$ & 3.19 \\
\hline 2 & $306 \pm 4.90$ & 1.60 & $315.08 \pm 11.03$ & 3.50 \\
\hline 3 & $204.06 \pm 4.06$ & 1.99 & $189.55 \pm 7.78$ & 4.10 \\
\hline
\end{tabular}

Concentration of SSc determined by ELISA. All data were mean \pm SD from six wells analysis of each sample.

Table 4: Contents of ssd determined by ELISA with anti-SSc MAb and HPLC

\begin{tabular}{|c|c|c|c|}
\hline $\begin{array}{l}\text { Traditional } \\
\text { Chinese } \\
\text { prescriptions }\end{array}$ & $\begin{array}{l}\text { Percentage } \\
\text { of Bupleuri } \\
\text { radix }\end{array}$ & $\begin{array}{l}\text { Composition of Kampo } \\
\text { medicine }\end{array}$ & $\begin{array}{l}\text { Concentration } \\
\text { of SSc }(\mu \mathrm{g} / \mathrm{g} \\
\text { dwt.) }\end{array}$ \\
\hline xiao-yao-san & $1 / 55$ & $\begin{array}{l}\text { Bupleuri radix } 1 \mathrm{~g} \text {, Paeoniae } \\
\text { radix alba } 12 \mathrm{~g} \text {, Angelica } \\
\text { sinensis } 12 \mathrm{~g} \text {, Poria } \\
12 \mathrm{~g} \text { Atractylodes } 6 \mathrm{~g} \text {, } \\
\text { Glycyrrhizae radix } 6 \mathrm{~g}\end{array}$ & $76.82 \pm 17.94$ \\
\hline Da-chai-hu-tang & $1 / 7$ & $\begin{array}{l}\text { Bupleuri radix } 12 \mathrm{~g}, \\
\text { Scutellariae radix } 9 \mathrm{~g}, \\
\text { Paeoniae radix alba } 9 \\
\mathrm{~g}, \text { Pinelliae rhizoma } 9 \mathrm{~g}, \\
\text { Aurantii fructus immaturus } 9 \\
\mathrm{~g}, \text { Zingiberis rhizoma recens } \\
15 \mathrm{~g}, \text { Jujubae fructus } 15 \mathrm{~g}, \\
\text { Rhei radix et rhizoma } 6 \mathrm{~g} .\end{array}$ & $83.54 \pm 7.86$ \\
\hline Si-ni-san & $1 / 4$ & $\begin{array}{l}\text { Bupleuri radix } 6 \mathrm{~g} \text {, Paeoniae } \\
\text { radix alba } 6 \mathrm{~g} \text {, Aurantii } \\
\text { fructus immaturus } 6 \mathrm{~g} \text {, } \\
\text { Glycyrrhizae radix } 6 \mathrm{~g}\end{array}$ & $26.71 \pm 5.01$ \\
\hline Bu-zhong-yi-qi-tang & $4 / 33$ & $\begin{array}{l}\text { Astragali radix } 16 \mathrm{~g} \text {, } \\
\text { Ginseng radix } 15 \mathrm{~g} \text {, } \\
\text { Atractylodis macrocephalae } \\
\text { rhizoma } 10 \mathrm{~g} \text {, Glycyrrhizae } \\
\text { radix } 15 \mathrm{~g} \text {, Cimicifugae } \\
\text { rhizoma } 6 \mathrm{~g} \text {, Bupleuri radix } \\
12 \mathrm{~g} \text {, Angelicae sinensis } \\
\text { radix } 10 \mathrm{~g} \text {, Citri reticulatae } \\
\text { pericarpium } 6 \mathrm{~g} \text {, Zingiberis } \\
\text { rhizoma recens } 5 \mathrm{~g} \text {, Jujubae } \\
\text { fructus } 5 \mathrm{~g}\end{array}$ & $34.20 \pm 4.82$ \\
\hline $\begin{array}{l}\text { Huang-lian-jie-du- } \\
\text { tang }\end{array}$ & 0 & $\begin{array}{l}\text { Scutellariae radix } 6 \text {, Coptidis } \\
\text { rhizome } 9 \mathrm{~g} \text {, Phellodendri } \\
\text { chinensis coptex } 6 \mathrm{~g} \text {, } \\
\text { Gardeniae fructus } 9 \mathrm{~g}\end{array}$ & $N^{b}$ \\
\hline \multicolumn{4}{|c|}{$\begin{array}{l}\text { All data are mean } \pm \text { SD from three wells analysis of each sample. } N^{b}=\text { not } \\
\text { detectable. }\end{array}$} \\
\hline
\end{tabular}

Table 5: Total concentration of saikosaponin c (SSc) in various traditional Chinese medicines determined by enzyme-linked immunosorbent assaya.

Table 2 shows the results of assay accuracy and variation. As expected, the intra-assay variations were lower than the inter-assay variations which may be due to variation of reagent preparation. The intra-assay RSDs were $<3.0 \%$, while the inter-assay RSDs were $<8.9 \%$, which indicate that this assay is very accurate and stable. As to assay recovery rate, SSc recoveries were $99.82-103.59 \%$ (mean, $101.71 \%$ ) (Table 3).

In order to confirm the correlation SSc determination between ELISA and HPLC, correlation coefficient was calculated by fitting a straight line from analyses by the ELISA and HPLC methods. Table 4 shows the correlation of SSc concentration using HPLC and ELISA indicating good correlation. We decided the newly established ELISA can be used for the determination of SSc concentration without any pretreatment.

Since theELISA assay was relatively quick, convenient, and economic compared with HPLC, we used it to determine the concentration of SSc in six prescriptions (Sini san, Xiao chai hu tang, Da cahi hu tang, Chai hu gui zhi tang, Bu zhong yi qi tang, and Huang lian jie du tang as shown in Table 5 with various Radix buplerui composition ratios without pretreatment. From these results, it is apparent that this ELISA method can be applied to determine SSc in medicine, which will be very useful and more convenient in product quality control and quantification in the future.

\section{Acknowledgements}

This work was supported by the National Natural Science Foundation of China (81274043, 81373542, 81473338, 81430102) and the Classical Prescription Basic Research Team of the Beijing University of Chinese Medicine.The authors declare no conflicts of interest.

\section{References}

1. Näreoja $T$, Vehniäinen $M$, Lamminmäki U, Hänninen $P E$, Härmä $H$ (2009) Study on nonspecificity of an immuoassay using Eu-doped polystyrene nanoparticle labels. J Immunol Methods 345: 80-89.

2. Zhu S, Shimokawa S, Shoyama Y, Tanaka H (2006) A novel analytica ELISA-based methodology for pharmacologically active saikosaponins. Fitoterapia 77: 100-108.

3. Zhu SH, Shimokawa S, Tanaka H, Shoyama Y (2004) Development of an assay system for saikosaponin a using anti-saikosaponin a monoclonal antibodies, Biological \& pharmaceutical bulletin 27: 66-71.

4. Lu Z, Morinaga O, Tanaka H, Shoyama Y (2003) A quantitative ELISA using monoclonal antibody to survey paeoniflorin and albiflorin in crude drugs and traditional Chinese herbal medicines, Biological \& pharmaceutical bulletin 26 862-866.

5. Ohgusu T, Hamase K, Tanaka H, Shoyama Y, Zaitsu K (2006) High-throughput determination of free $\mathrm{D}$-aspartic acid in mammals by enzyme immunoassay using specific monoclonal antibody, Analytical biochemistry 357: 15-20.

6. Qu H, Wang Y, Shan W, Zhang Y, Feng H, et al. (2015) Development of ELISA for detection of Rh1 and Rg2 and potential method of immunoaffinity chromatography for separation of epimers. J Chromatogr B Analyt Techno Biomed Life Sci 985: 197-205.

7. Zhao $Y, Q u ~ H$, Zhang $Y$, Sun Y, Feng H, et al. (2015) Enzyme-linked immunosorbent assay for hyodeoxycholic acid in pharmaceutical products using a monoclonal antibody. Analytical Letters 48: 1285-1296.

8. Qu H, Zhang G, Li Y, Sun H, Sun, Y, et al. (2014) Development of an enzymelinked immunosorbent assay based on anti-puerarin monoclonal antibody and its applications. Journal of chromatography B. Analytical technologies in the biomedical and life sciences 953-954: 120-125.

9. Qu H, Sai J, Wang Y, Sun Y, Zhang Y, et al. (2014) Establishment of an enzymelinked immunosorbent assay and application on determination of ginsenoside Re in human saliva. Planta Med 80: 1143-1150.

10. Qu HH, Sun Y, Wu TT, Zhang GL, Cheng JJ, et al. (2014) Pharmacokinetics of geniposide by monoclonal antibody-based icELISA in mice after oral administration of Huanglian-Jiedu-Tang. Biological \& pharmaceutical bulletin 37: $1525-1533$

11. Lee TH, Chang J, Kim BM (2014) Saikosaponin C inhibits lipopolysaccharide induced apoptosis by suppressing caspase- 3 activation and subsequen degradation of focal adhesion kinase in human umbilical vein endothelial cells. Biochemical and biophysical research communications 44: 615-621.

12. Lee KJ, Xu MY, Shehzad O, Seo EK, Kim YS (2014) Separation of triterpenoid saponins from the root of Bupleurum falcatum by counter current chromatography: the relationship between the partition coefficients and solven system composition. Journal of separation science 37: 3587-3594.

13. Li XQ, Gao QT, Chen XH, Bi KS (2005) High performance liquid chromatographic assay of saikosaponins from radix Bupleuri in China. Biol Pharm Bull 28: 1736-1742.

14. Ishiyama M, Shoyama Y, Murakami H, Shinohara H (1995) Production of monoclonal antibodies and development of an ELISA for solamargine. Cytotechnology 18: 153-158.

15. Schreck RR, Warburton D, Miller OJ, Beiser SM, Erlanger BF (1973) Chromosome structure as revealed by a combined chemical and immunochemical procedure. Proc Natl Acad Sci U S A 70: 804-807.

16. Liu HF, Ma J, Winter C, Bayer R (2010) Recovery and purification process development for monoclonal antibody production. MAbs 2: 480-499.

17. Weiler EW and Zenk MH (1976) Radioimmunoassay for the determination of digoxin and related compounds in Digitalis lanata. Phytochemistry 1: 1537-1545. 